Department of Economics Finance \& Accounting

Working Paper N273-16

\title{
Environment, Imperfect Competition, and Trade: Insights for Optimal Policy in General Equilibrium
}

by

\author{
Rudy Colacicco
}

Maynooth University 


\title{
Environment, Imperfect Competition, and Trade: Insights for Optimal Policy in General Equilibrium*
}

\author{
by Rudy Colacicco ${ }^{\text {a }}$ \\ ${ }^{a}$ Department of Economics, Finance and Accounting, Maynooth University
}

July 28, 2016

\begin{abstract}
I build a two-country general oligopolistic equilibrium model, in which sectors differ in emissions and technologies, and pollution can be transboundary. I derive the optimal bilateral environmental policy for the economy as a whole, for the cases in which the environmental damage either linearly or quadratically increases in total pollution. The analysis highlights that the optimal emission tax can even be negative, and bilateral trade liberalization should be matched with either a rise or a fall in the optimal emission tax. The moments of the emission distribution and technology distribution across sectors are fundamental to implement optimal environmental policies.
\end{abstract}

Keywords: Cournot Competition; Environmental Policy; Emission Tax; General Oligopolistic Equilibrium (GOLE); Trade Liberalization; Transboundary Pollution

JEL Codes: F12; F13; F18; Q53; Q56; Q58

*I am grateful to Dermot Leahy for useful comments and suggestions. For financial support I thank the Irish Research Council [grant number GOIPD/2015/330].

${ }^{\dagger}$ Address for Correspondence: Department of Economics, Finance and Accounting, Maynooth University National University of Ireland Maynooth, Rhetoric House, South Campus, Maynooth, Co. Kildare, Ireland; email: rudy.colacicco@nuim.ie; fax: (+353) (0) 17083934. 


\section{Introduction}

The environment has increasingly become a key topic for policymakers. In fact, they increasingly care not just about pollution generated within their own economy but also about the transboundary effects of pollution produced elsewhere in the world. Environmental policy is able to change the balance of competition in many sectors and, in turn, the demands for production factors. Given the oligopolistic nature of many sectors of several economies, ${ }^{1}$ it is interesting and useful to analyze the environmental policy in a full-fledged multi-sector general equilibrium model of international trade with imperfect (strategic) competition. A theoretical framework to consider environmental policy in general equilibrium can generate relevant findings for a better policy implementation.

The adoption of oligopolistic competition to analyze environmental issues is wellestablished in literature. For example, the first studies of strategic environmental policies date back to the first half of the 1990s (e.g., Ulph, 1992, Conrad, 1993, Barrett, 1994, Kennedy, 1994, Rauscher, 1994). ${ }^{2}$ Nevertheless, earlier studies have looked at cases in which policymakers can credibly pre-commit and unilaterally (non-cooperatively) choose the optimal environmental policy for a single sector to help domestic firms in competing with foreign ones. Nevertheless, this literature is in partial equilibrium and does not consider feedback from factor markets. ${ }^{3}$ This fact was probably due to the dearth of full-fledged general equilibrium frameworks in which to embed oligopolistic competition in a theoretically consistent way. ${ }^{4}$ Since then a theoretically consistent approach to embed oligopoly in general equilibrium has been developed. This approach relies on the concept of general oligopolistic equilibrium (hereafter GOLE) as developed by Neary (2003a;b), in which the economy is assumed to be composed by a continuum of oligopolistic sectors linked through factor markets. ${ }^{5}$

In this paper, I study how environmental and trade policies interact. To do so, I adopt the GOLE approach. The only study that also adopts the GOLE approach to study environmental

\footnotetext{
${ }^{1}$ For a recent and wide empirical evidence see, for example, Mayer and Ottaviano (2008).

${ }^{2}$ See Ulph (1994), Sturm (2003), and Requate (2005) for surveys of this literature and subsequent contributions.

${ }^{3}$ Much of the partial equilibrium literature of international trade and imperfect competition additionally abstracts from consumption, by adopting a third-country framework.

${ }^{4} \mathrm{~A}$ first intuitive attempt to embed strategic environmental policy in general equilibrium was provided by Rauscher (1994) in a third-country framework. Subsequent studies (e.g., Elbers and Withagen, 2002; 2003) have also addressed the consumption, by relying on numerical simulations, without providing closed-form solutions. As better explained below, the general equilibrium concept adopted in this paper is different from the one in which an outside sector plays the role of numéraire (e.g., Markusen et al., 1993). For further discussion on the issue of the outside sector in oligopoly studies see, for example, Leahy and Neary (2011).

${ }^{5}$ For details on the GOLE approach, see also Neary (2016). Colacicco (2015) provides a comprehensive survey of the GOLE applications.
} 
issues is the one of Richter (2014). Nevertheless, he focuses on the optimal environmental policy for single sectors. In a framework with segmented markets and perceived environmental damage as a linear function of the total pollution, Richter replicates a partial equilibrium analysis, and studies how partial trade liberalisation affects environmental policies in general equilibrium. He assumes that policymakers have perfect information on single markets and set environmental policies (i.e., emission taxes) at the sector level, to maximize sectoral welfare, which is given by the standard form as derived in partial equilibrium. ${ }^{6}$ This means that policymakers have not a global knowledge of the economy in which they operate (e.g., how national income and factor rewards are affected by their policies).

Dixit and Grossman (1986) highlighted the empirical difficulty in obtaining the necessary information for targeting sectors. ${ }^{7}$ So far, the GOLE literature has disregarded a more direct role of policymakers, and how they interact to set their policies for the economy as a whole. An exception is provided by Palokangas (2015), who focuses on interacting policymakers to analyze how wages are endogenously determined. However, unlike the present paper, he does not look at policies to affect the economy as a whole.

I do not consider optimal policy decisions at the sector level. Instead, in the model I present here, policymakers can levy only emission taxes to affect their economies as a whole, assuming that these policies are uniform across sectors (viz., no sector targeting). I consider that the perceived environmental damage can be either a linear function of the total pollution, as in Richter (2014), or a convex (quadratic) one. In addition, unlike Richter (2014) who assumes that all sectors have the same emission rate and use the same technology, I allow sectors to differ both in emission rates and technologies. These features cannot, of course, be addressed in a partial equilibrium (single-sector) analysis. I am interested in deriving the optimal environmental policy for two countries as a whole (i.e., cooperative equilibrium), because it is much more difficult to reach an efficient policy with non-cooperative countries and transboundary pollution. For the rest, I adopt the simplest possible theoretical set-up to convey insights. ${ }^{8}$

The paper continues as follows. The next section presents a general equilibrium model with

\footnotetext{
${ }^{6}$ In partial equilibrium studies, welfare is given by the sum of consumer surplus, producer surplus, revenues from import tariffs and emission taxes, as well as environmental damage.

${ }^{7}$ See also Flam and Helpman (1987) and Krugman (1987).

${ }^{8}$ Richter (2014) distinguishes between sectors open and closed to international trade, in which more than two oligopolistic firms compete. I adopt two simplifications: i) all sectors are open to international trade; ii) international duopoly takes place therein. The main ingredients of the framework presented here are adopted by many partial equilibrium studies: two countries, segmented markets, oligopolistic (Cournot) competition, transboundary pollution from production, and governments can levy import tariffs and emission taxes.
} 
many segmented markets in which firms strategically compete and generate pollution, which can be transboundary. I begin with the simplest framework to lay the groundwork for the other sections: the optimal environmental policy is derived for the case in which the perceived environmental damage is a linear function of the total pollution and sectors use the same technology but differ in emission rates. In Section 3, the analysis is extended to consider technologically heterogeneous sectors. In Section 4, I consider the alternative assumption concerning the perceived environmental damage as a convex (quadratic) function of total pollution. Section 5 concludes.

\section{Basic model}

Two identical countries, $\mathrm{H}$ and F, trade homogeneous goods. I focus on H's equations. Similar equations hold for F. Asterisked variables refer to F. ${ }^{9}$ For the moment, I assume that the perceived environmental damage is a linear function of the total pollution, and sectors use the same technology but differ in emission rates. To focus on this paper's goal, I abstract from abatement technology issues.

\subsection{Preferences: consumption and environmental damage}

The representative consumer in $\mathrm{H}$ is endowed with $L$ units of labor, inelastically supplied (for a wage rate, $w>0$ ) to a perfectly competitive labor market. Preferences are given by a utility function over outputs of a continuum of sectors of unit mass indexed by $z \in[0,1]$, and over the perceived environmental damage from total pollution:

$$
U[\{x(z)\},\{D(z)\}]=\int_{0}^{1} a x(z)-\frac{1}{2}[x(z)]^{2} d z-\alpha \int_{0}^{1} D(z) d z
$$

with $a>0$ and $x(z)$ the consumption of the good produced in sector $z$. The parameter $\alpha \geq 0$ accounts for the environmental concern (i.e., marginal disutility of total pollution). The perceived environmental damage (or negative externality) is given by the sum (i.e., integral) of the pollution from each sector, $D(z)$.

Production in each sector generates proportional pollution such that $D(z) \equiv d(z)+\beta d^{*}(z)$, with $d(z) \equiv \gamma(z)\left[y_{H}(z)+y_{F}(z)\right]$ and $d^{*}(z) \equiv \gamma(z)\left[y_{H}^{*}(z)+y_{F}^{*}(z)\right]$, where $y_{H}(z)$ and $y_{F}(z)$

\footnotetext{
${ }^{9} \mathrm{~A}$ file for all mathematical derivations and numerical simulations is available from the author upon request.
} 
stand for the $\mathrm{H}$ firm's output in sector $z$ sold in $\mathrm{H}$ and $\mathrm{F}$, respectively, as well as $y_{H}^{*}(z)$ and $y_{F}^{*}(z)$ stand for the $\mathrm{F}$ firm's output in sector $z$ sold in $\mathrm{H}$ and $\mathrm{F}$, respectively. The parameter $\beta \in[0,1]$ represents the transboundary pollution rate, assuming it is the same for both countries. ${ }^{10}$

The consumer maximizes Eq. (1) subject to the budget constraint. Unlike governments, consumers are too small to internalize the environmental damage in their decisions. Hence, the representative consumer does not consider the environmental damage in her problem:

$$
\max _{x(z) \in \mathbb{R}_{+}, z \in[0,1]} U[\{x(z)\}, \cdot] \quad \text { s.t. } \quad \int_{0}^{1} p(z) x(z) d z \leq I,
$$

where $I$ stands for national income and $p(z)$ stands for the price of $x(z)$ sold in H. Solving the consumer's problem in Eq. (2) gives the linear inverse demand function for the interior optimal consumption of $x(z):^{11}$

$$
\lambda p(z)=a-x(z)
$$

where $\lambda$ stands for the marginal utility of national income. I assume throughout that $p(z)>0$ for any $z$, and non satiation $(\lambda>0) .{ }^{12}$ As standard in the GOLE literature, I choose $\lambda$ as numéraire $(\lambda=1)$.

\subsection{Partial equilibrium: technology, production, and pollution}

Governments are able to pre-commit credibly to their policies before firms compete. I begin from the competition within sectors. Firms compete à la Cournot, taking as given factor rewards and policies. Labor can costlessly move across sectors, therefore the wage rates are determined at the country level. Nevertheless, labor cannot migrate abroad. For the moment, I assume that $\mathrm{H}$ and $\mathrm{F}$ firms in each sector use the same technology with constant returns to scale. I normalize the unit labor requirement to unity for all firms. Nevertheless, firms across sectors differ in their emission rate, $\gamma(z)$, for each unit of output they produce.

Product markets are segmented. Trade barriers are given by a specific (per-unit) import tar-

\footnotetext{
${ }^{10}$ For $\beta>0$ one can think of, for example, ammonia $\left(\mathrm{NH}_{3}\right)$, carbon dioxide $\left(\mathrm{CO}_{2}\right)$, carbon monoxide $(\mathrm{CO})$, methane $\left(\mathrm{CH}_{4}\right)$, nitrogen oxides $\left(\mathrm{NO}_{\mathrm{X}}\right)$, sulphur dioxide $\left(\mathrm{SO}_{2}\right)$, volatile organic compounds, or persistent organic pollutants.

${ }^{11}$ Sub-utility functions are strictly concave, therefore first-order conditions for utility maximization are both necessary and sufficient.

${ }^{12}$ In general equilibrium $\lambda$ is endogenous and depends on prices and national income.
} 
iff, $t$, common (uniform) across sectors. ${ }^{13}$ The same structure is adopted for the emissions tax, $\tau$. I assume that duopolistic competition between $\mathrm{H}$ firm and $\mathrm{F}$ firm takes place in all sectors. ${ }^{14}$ Given the cooperative behavior of the governments for the equilibrium under analysis, one can set $\tau=\tau^{*}$ in the profit functions. As the focus of the paper is on the environmental policy, I also set $t=t^{*}$ and treat import tariffs as exogenous (e.g., fixed by a trade agreement). Firms in $\mathrm{H}$ maximize their own profits subject to the (perceived) inverse demand functions in Eq. (3), by taking as given direct rivals' outputs, policies, and wage rates:

(4) $\max _{y_{H}(z), y_{F}(z) \in \mathbb{R}_{+}, z \in[0,1]} \pi(z) \equiv[p(z)-w-\tau \gamma(z)] y_{H}(z)+\left[p^{*}(z)-w-\tau \gamma(z)-t\right] y_{F}(z)$.

Firms in F similarly solve

$$
\max _{y_{H}^{*}(z), y_{F}^{*}(z) \in \mathbb{R}_{+}, z \in[0,1]} \pi^{*}(z) \equiv\left[p^{*}(z)-w^{*}-\tau \gamma(z)\right] y_{F}^{*}(z)+\left[p(z)-w^{*}-\tau \gamma(z)-t\right] y_{H}^{*}(z),
$$

subject to the (perceived) inverse demand functions of the representative consumer in F, similar to Eq. (3).

Imposing market clearing conditions and deriving first-order conditions from firms' problems in Eqs. (4) and (5) yields firms' best response functions in any sector. ${ }^{15}$ Solving the given system of first-order conditions yields the Cournot-Nash equilibrium outputs for any $\mathrm{H}$ firm and $\mathrm{F}$ firm that sell in $\mathrm{H}$ :

$$
y_{H}(z)^{C N}=\frac{a-2 w+w^{*}+t-\tau \gamma(z)}{3}
$$

and

$$
y_{H}^{*}(z)^{C N}=\frac{a+w-2 w^{*}-2 t-\tau \gamma(z)}{3},
$$

where $C N$ stands for Cournot-Nash equilibrium. The Cournot-Nash equilibrium outputs for

\footnotetext{
${ }^{13}$ Specific import tariffs can isomorphically represent other per-unit trade frictions. Hummels and Skiba (2004) and Irarrazabal et al. (2015) provide evidence for the empirical relevance of additive trade costs. The World Trade Report 2012 (WTO, 2012) highlights the importance of non-tariff measures. See also Baldwin and Evenett (2009) and Kee et al. (2009).

${ }^{14}$ International duopoly is adopted by other GOLE studies whenever the focus is not on competition policy (e.g., Bastos and Straume, 2012, Neary and Tharakan, 2012, Egger et al., 2015). Duopoly is also commonly assumed in the literature of environmental economics.

${ }^{15}$ Second-order conditions for interior solutions are satisfied, as profits are strictly concave functions in outputs.
} 
any $\mathrm{H}$ firm and $\mathrm{F}$ firm that sell in $\mathrm{F}$ are

$$
y_{F}(z)^{C N}=\frac{a-2 w+w^{*}-2 t-\tau \gamma(z)}{3}
$$

and

$$
y_{F}^{*}(z)^{C N}=\frac{a+w-2 w^{*}+t-\tau \gamma(z)}{3} .
$$

\subsection{General equilibrium: labor markets and wages}

Without loss of generality, wage income and aggregate profits are costlessly distributed to the consumer. Revenue from import tariffs and emission taxes is returned to the consumer as a lump sum. As $\mathrm{H}$ and $\mathrm{F}$ are identical, $L=L^{*}$. With full employment, the labor market clearing condition for $\mathrm{H}$ is

$$
L=\int_{0}^{1}\left[y_{H}(z)+y_{F}(z)\right] d z
$$

and for $\mathrm{F}$ is

$$
L=\int_{0}^{1}\left[y_{H}^{*}(z)+y_{F}^{*}(z)\right] d z .
$$

Using Eqs. (6)-(9) and solving simultaneously the labor market clearing conditions for both wage rates yields

$$
w=w^{*}=\frac{2 a-3 L-t-2 \tau \mu_{1}^{\gamma}}{2} \equiv W
$$

with $\mu_{1}^{\gamma} \equiv \int_{0}^{1} \gamma(z) d z$.

Any firm's Cournot-Nash equilibrium outputs are therefore

$$
y_{H}(z)^{C N}=\frac{a-W+t-\tau \gamma(z)}{3}=y_{F}^{*}(z)^{C N}
$$

and

$$
y_{F}(z)^{C N}=\frac{a-W-2 t-\tau \gamma(z)}{3}=y_{H}^{*}(z)^{C N}
$$

This implies $d(z)=d^{*}(z)$ for any $z$. Notice that $p(z)^{C N}=p^{*}(z)^{C N}$ for any $z$, guaranteeing 
balanced trade, given Eq. (12). ${ }^{16}$

\subsection{Social welfare and optimal environmental policy}

The representative consumer approach with quasi-homothetic preferences allows deriving social welfare through the indirect utility function. The latter can be obtained by inverting Eq. (3), plugging these direct demand functions into Eq. (1), and recalling the definition of $D(z)$, which can be written as $D(z)=(1+\beta) \gamma(z)[a-p(z)]$.

Abstracting from some constants, the indirect utility function is

$$
V \equiv-\mu_{2}^{p}+\alpha(1+\beta) \int_{0}^{1} \gamma(z) p(z) d z
$$

with $\mu_{2}^{p} \equiv \int_{0}^{1}[p(z)]^{2} d z .{ }^{17}$ Using Eqs. (10)-(12), one can write Eq. (13) in equilibrium in terms of exogenous variables and parameters as (abstracting from some constants)

$$
V=-\frac{4}{9} \xi^{\gamma} \tau^{2}+\frac{2}{3} \alpha(1+\beta) \xi^{\gamma} \tau
$$

with $\xi^{\gamma} \equiv \mu_{2}^{\gamma}-\left(\mu_{1}^{\gamma}\right)^{2}$ and $\mu_{2}^{\gamma} \equiv \int_{0}^{1}[\gamma(z)]^{2} d z$. Once the general equilibrium feedback is taken into account, and all adjustment effects are aggregated across sectors, social welfare is independent of the import tariff.

Next, I analyze the first stage of the game, in which governments set their environmental policies and are aware of their economies as a whole. Hence, the first-order condition to maximize $V$ in Eq. (14) with respect to $\tau$ is ${ }^{18}$

$$
\frac{\partial V}{\partial \tau}=0=\xi^{\gamma}\left[-\frac{8}{9} \tau+\frac{2}{3} \alpha(1+\beta)\right]
$$

\footnotetext{
${ }^{16}$ Given that $\mathrm{H}$ and $\mathrm{F}$ share the wage rate, and that $\mathrm{H}$ and $\mathrm{F}$ firms in each sector produce the same output for their domestic and foreign markets, then $\mathrm{H}$ and $\mathrm{F}$ also share Cournot-Nash aggregate profits and the revenue from import tariffs and emission taxes. Hence, $\mathrm{H}$ and $\mathrm{F}$ share the national income. This means they also share the marginal utility of national income. This allows to derive closed-form solutions without introducing the foreign marginal utility of national income, as $\lambda=\lambda^{*}=1$.

${ }^{17}$ The parameter $\alpha$ can be endogenous and derived in a political economy framework. Nevertheless, Baldwin (1987) showed that exogenous weights in governments' objective functions are equivalent to those originated from more explicit considerations of political economy.

${ }^{18}$ Being $\mathrm{H}$ and $\mathrm{F}$ identical, the situation in which governments cooperate to maximize their joint social welfare is equivalent to the one in which one maximizes one country's social welfare (that is, $\arg \max _{\tau} 2 V \equiv \arg \max _{\tau} V$ ).
} 
Therefore, for $\xi^{\gamma}>0$ the optimal emission tax is: ${ }^{19}$

$$
\tau^{A}=\frac{3}{4} \alpha(1+\beta) \geq 0
$$

If $\alpha>0$, then the optimal bilateral emission tax for both economies as a whole is positive and monotonically increasing in the transboundary pollution rate and environmental concern.

The fact that social welfare is unaffected by changes in the import tariff is unsatisfactory, and due to the assumption that all sectors use the same technology. ${ }^{20}$ Hence, in the next section, I address this issue and relax this assumption, by introducing technologically heterogeneous sectors.

\section{Technologically heterogeneous sectors}

Assume that firms in each sector use a specific unit labor requirement $h(z)$. Then, firms in $\mathrm{H}$ maximize their own profits as before:

$\max _{y_{H}(z), y_{F}(z) \in \mathbb{R}_{+}, z \in[0,1]} \pi(z) \equiv[p(z)-w h(z)-\tau \gamma(z)] y_{H}(z)+\left[p^{*}(z)-w h(z)-\tau \gamma(z)-t\right] y_{F}(z)$.

Firms in F similarly solve

$\max _{y_{H}^{*}(z), y_{F}^{*}(z) \in \mathbb{R}_{+}, z \in[0,1]} \pi^{*}(z) \equiv\left[p^{*}(z)-w^{*} h(z)-\tau \gamma(z)\right] y_{F}^{*}(z)+\left[p(z)-w^{*} h(z)-\tau \gamma(z)-t\right] y_{H}^{*}(z)$

The corresponding Cournot-Nash equilibrium outputs are

$$
y_{H}(z)^{C N}=\frac{a-2 w h(z)+w^{*} h(z)+t-\tau \gamma(z)}{3},
$$

$$
y_{H}^{*}(z)^{C N}=\frac{a+w h(z)-2 w^{*} h(z)-2 t-\tau \gamma(z)}{3},
$$

$$
y_{F}(z)^{C N}=\frac{a-2 w h(z)+w^{*} h(z)-2 t-\tau \gamma(z)}{3},
$$

\footnotetext{
${ }^{19}$ For $\xi^{\gamma}>0$ the second-order condition for a maximum is satisfied.

${ }^{20}$ Neary (2003a;b) named this situation "featureless economy".
} 
and

$$
y_{F}^{*}(z)^{C N}=\frac{a+w h(z)-2 w^{*} h(z)+t-\tau \gamma(z)}{3} .
$$

With full employment, the labor market clearing condition for $\mathrm{H}$ is

$$
L=\int_{0}^{1}\left[y_{H}(z)+y_{F}(z)\right] h(z) d z
$$

and for $\mathrm{F}$ is

$$
L=\int_{0}^{1}\left[y_{H}^{*}(z)+y_{F}^{*}(z)\right] h(z) d z .
$$

Using Eqs. (16)-(19) and solving simultaneously the labor market clearing conditions for both wage rates yields

$$
w=w^{*}=\frac{2 a \mu_{1}^{h}-3 L-t \mu_{1}^{h}-2 \tau \theta}{2 \mu_{2}^{h}} \equiv W,
$$

with $\mu_{1}^{h} \equiv \int_{0}^{1} h(z) d z, \mu_{2}^{h} \equiv \int_{0}^{1}[h(z)]^{2} d z$, and $\theta \equiv \int_{0}^{1} h(z) \gamma(z) d z$.

Any firm's Cournot-Nash equilibrium outputs are therefore

$$
y_{H}(z)^{C N}=\frac{a-W h(z)+t-\tau \gamma(z)}{3}=y_{F}^{*}(z)^{C N}
$$

and

$$
y_{F}(z)^{C N}=\frac{a-W h(z)-2 t-\tau \gamma(z)}{3}=y_{H}^{*}(z)^{C N} .
$$

As before, the symmetry of the equilibrium guarantees balanced trade. Using Eqs. (20)(22), one can derive social welfare in Eq. (13) in terms of exogenous variables and parameters. As the expression of social welfare is cumbersome, I do not report it here. The first-order condition to maximize social welfare yields the optimal emission tax

$$
\tau^{B}=\tau^{A}+\frac{(a+t)\left(\mu_{1}^{h} \theta-\mu_{1}^{\gamma} \mu_{2}^{h}\right)}{2\left(\mu_{2}^{\gamma} \mu_{2}^{h}-\theta^{2}\right)} .
$$

The denominator of the second term in Eq. (23) is positive, given the Cauchy-Schwarz inequality, which also guarantees that the second-order condition for a maximum is satisfied. ${ }^{21}$ The

\footnotetext{
${ }^{21}$ The second-order condition for a maximum in $\tau^{B}$ is $\theta^{2}-\mu_{2}^{\gamma} \mu_{2}^{h}<0$. I assume strict negativity of the
} 
numerator of the second term in Eq. (23) can be either positive or negative. Hence, $\tau^{B}$ can be either larger or smaller than $\tau^{A} \cdot{ }^{22}$ Yet, $\tau^{B}$ can be negative as well, as shown in the following numerical simulation.

The values of the parameters are arbitrarily chosen to have a positive equilibrium wage rate and interior solutions (i.e., positive equilibrium productions in any domestic and export markets as well as positive equilibrium prices): $a=200, L=105, \alpha=0.5$, and $\beta=0.6$. Assume that the emission rate is increasing in the unit labor requirement. Hence, assume furthermore that the emission distribution is given by $\gamma(z)=1+z^{2}$ and the technology distribution is given by $h(z)=e^{z} \cdot{ }^{23}$ These distributions have the following moments (i.e., integrals for $z$ from 0 to 1) relevant for the analysis: $\left[\mu_{1}^{\gamma}, \mu_{2}^{\gamma}, \mu_{1}^{h}, \mu_{2}^{h}, \theta\right]=\left[\frac{4}{3}, \frac{28}{15},(e-1), \frac{1}{2}\left(e^{2}-1\right),(2 e-3)\right]$. For simplicity, assume free trade $(t=0)$. Then, $\tau^{B}=-275.949$, with $w=268.748, y_{H}(z)^{C N}=$ $y_{F}(z)^{C N}=66.6667+91.9831 \gamma(z)-89.5828 h(z)$, and $p(z)^{C N}=66.6667-183.966 \gamma(z)+$ $179.166 h(z)$.

Notice that in case policymakers are not aware at all of the environmental damage $(\alpha=0)$, $\tau^{A}$ would be zero (see Eq. (15)), but $\tau^{B}$ can continue to differ from zero. This fact highlights that emission taxes play a role in industrial policy for the economy as a whole in general equilibrium, independently of environmental concerns. This is due to the introduced heterogeneity in the technology across sectors, opening the possibility to have reallocation of labor (whose supply is fixed) among sectors after policy changes.

As $\tau^{B}$ is positively related to $\tau^{A}$, one has that $\tau^{B}$ is monotonically increasing in the transboundary pollution rate and environmental concern. Last, notice that $\operatorname{sgn}\left(\partial \tau^{B} / \partial t\right)=$ $\operatorname{sgn}\left(\mu_{1}^{h} \theta-\mu_{1}^{\gamma} \mu_{2}^{h}\right)$. This means that bilateral trade liberalization should be matched with either a rise or a fall in the optimal emission tax. ${ }^{24}$ For the special case in which the emission distribution and technology distribution are independent (i.e., uncorrelated), then $\theta=\mu_{1}^{h} \mu_{1}^{\gamma}$ and $\mu_{1}^{h} \theta-\mu_{1}^{\gamma} \mu_{2}^{h}<0$, therefore $\partial \tau^{B} / \partial t<0$. Namely, if technologies and emissions are uncorrelated across sectors, then bilateral trade liberalization should be matched with a rise in the emission tax.

second-order condition to avoid the denominator of the second term in Eq. (23) would be null.

${ }^{22}$ For the special case in which all sectors use the same technology, $\xi^{h} \equiv \mu_{2}^{h}-\left(\mu_{1}^{h}\right)^{2}=0$ and $\theta=\mu_{1}^{\gamma}$ (normalizing $\mu_{1}^{h}$ to unity as done before), therefore $\tau^{B}$ reduces to $\tau^{A}$.

${ }^{23}$ These distribution forms have been also adopted by other GOLE studies to represent the technology in numerical simulations (e.g., Egger and Etzel, 2012). One needs to assume two different distributions for the technology and emissions to avoid the denominator of the second term in Eq. (23) would be null.

${ }^{24}$ This ambiguous finding, though in partial equilibrium, has been highlighted by Burguet and Sempere (2003). 


\section{Environmental damage as a convex function of the total pollution}

Here I consider the alternative, yet well-established in partial equilibrium studies (e.g., Kennedy, 1994), assumption concerning the perceived environmental damage as a convex function of the total pollution. To obtain closed-form solutions, I adopt the quadratic form. Hence, the utility function in Eq. (1) is simply modified as follows:

$$
U[\{x(z)\},\{D(z)\}]=\int_{0}^{1} a x(z)-\frac{1}{2}[x(z)]^{2} d z-\alpha\left[\int_{0}^{1} D(z) d z\right]^{2}
$$

For the case in which all sectors share the technology (using Eqs. (10)-(12)), the indirect utility function in equilibrium in terms of exogenous variables and parameters is

$$
V=-\frac{4}{9} \xi^{\gamma} \tau^{2}-\frac{\alpha}{9}(1+\beta)^{2}\left(3 L \mu_{1}^{\gamma}-2 \xi^{\gamma} \tau\right)^{2}
$$

The first-order condition to maximize $V$ in Eq. (24) with respect to $\tau$ is

$$
\frac{\partial V}{\partial \tau}=0=\xi^{\gamma}\left[-\frac{8}{9} \tau+\frac{4}{9} \alpha(1+\beta)^{2}\left(3 L \mu_{1}^{\gamma}-2 \xi^{\gamma} \tau\right)\right]
$$

Therefore, for $\xi^{\gamma}>0$ the optimal emission tax is: $:^{25}$

$$
\tau^{C}=\frac{3 \alpha(1+\beta)^{2} L \mu_{1}^{\gamma}}{2\left[1+\alpha(1+\beta)^{2} \xi^{\gamma}\right]}=\tau^{A} \frac{2(1+\beta) L \mu_{1}^{\gamma}}{1+\alpha(1+\beta)^{2} \xi^{\gamma}} \geq 0 .
$$

For $\alpha>0$ the optimal bilateral emission tax for both economies as a whole continues to be positive and monotonically increasing in the transboundary pollution rate and environmental concern.

For the case of technologically heterogeneous sectors, the expression of social welfare is cumbersome, therefore it is not reported here. The first-order condition to maximize social welfare yields the following optimal emission tax: ${ }^{26}$

$$
\tau^{D}=\frac{1}{\Omega}\left(\begin{array}{c}
a\left(\mu_{1}^{\gamma} \mu_{2}^{h}-\mu_{1}^{h} \theta\right)\left(\left(-1+2 \alpha(1+\beta)^{2} \mu_{2}^{\gamma}\right) \mu_{2}^{h}-2 \alpha(1+\beta)^{2} \theta^{2}\right)- \\
\mu_{1}^{\gamma} \mu_{2}^{h} t\left(\left(1+\alpha(1+\beta)^{2} \mu 2^{\gamma}\right) \mu_{2}^{h}-\alpha(1+\beta)^{2} \theta^{2}\right)+\theta\left(\mu_{1}^{h} \mu_{2}^{h} t+\alpha(1+\beta)^{2}\left(3 L+\mu_{1}^{h} t\right)\left(\mu_{2}^{\gamma} \mu_{2}^{h}-\theta^{2}\right)\right)
\end{array}\right),
$$

\footnotetext{
${ }^{25}$ For $\xi^{\gamma}>0$ the second-order condition for a maximum is satisfied.

${ }^{26}$ The second-order condition for a maximum is satisfied given the Cauchy-Schwarz inequality.
} 
where $\Omega \equiv 2\left(\mu_{2}^{\gamma} \mu_{2}^{h}-\theta^{2}\right)\left\{\left[1+\alpha(1+\beta)^{2} \mu_{2}^{\gamma}\right] \mu_{2}^{h}-\alpha(1+\beta)^{2} \theta^{2}\right\}>0$. The optimal emission $\operatorname{tax}, \tau^{D}$, can continue to be negative. ${ }^{27}$ For example, consider the following numerical simulation for a free trade scenario. Let $a=200, L=105, \alpha=0.1, \beta=0.6, \gamma(z)=1+z^{2}$, and $h(z)=e^{z}$. With respect to the previous simulation, the only change is a smaller $\alpha$. Then, $\tau^{D}=$ -244.177 , with $w=244.469, y_{H}^{C N}(z)=y_{F}^{C N}(z)=66.6667+92.1431 \gamma(z)-89.7048 h(z)$, and $p(z)^{C N}=66.6667-184.286 \gamma(z)+179.41 h(z)$.

As before, in case governments are not aware at all of the environmental damage $(\alpha=0)$, $\tau^{D}$ can continue to differ from zero. ${ }^{28}$ One can show that $\operatorname{sgn}\left(\partial \tau^{D} / \partial \alpha\right)=\operatorname{sgn}\left(\partial \tau^{D} / \partial \beta\right)=$ $\operatorname{sgn}\left(a \mu_{1}^{\gamma} \mu_{2}^{h}+L \theta-a \mu_{1}^{h} \theta\right)$. Last, as before when sectors are technologically heterogeneous, $\operatorname{sgn}\left(\partial \tau^{D} / \partial t\right)=\operatorname{sgn}\left(\mu_{1}^{h} \theta-\mu_{1}^{\gamma} \mu_{2}^{h}\right)$.

\section{Concluding remarks}

The literature on environmental policy and imperfect competition (mostly strategic environmental policy) has relied so far on partial equilibrium analyses. This is the first study that addresses the environmental policy for the economy as a whole, in a full-fledged general equilibrium model of international trade with oligopolistic competition within many sectors, deriving closed-form solutions. I have provided a simple model to study how import tariffs and emission taxes interact.

The model derives the optimal bilateral environmental policy, but it does not provide a final statement on its sign. Indeed, the model highlights that the exact values of the moments of the emission distribution and technology distribution across sectors are fundamental to understand the exact environmental policy to be implemented. The only case in which the model indicates a positive emission tax is when all sectors use the same technology. When sectors are technologically heterogeneous, something that cannot be addressed in partial equilibrium analysis of single sectors, the emission tax can be negative as well. Future empirical research should study how pollution intensities and technologies (i.e., requirements of production factors) are interrelated. However, the model suggests that emission taxes could be wrong or detrimental for social welfare. This does not mean that one should give subsidies to polluters. Instead, to limit the environmental damage this paper's findings highlight that alternative policy tools can

\footnotetext{
${ }^{27}$ For the special case in which all sectors use the same technology, $\xi^{h}=0$ and $\theta=\mu_{1}^{\gamma}$ (normalizing $\mu_{1}^{h}$ to unity), therefore $\tau^{D}$ reduces to $\tau^{C}$.

${ }^{28}$ For $\alpha=0$ one has that $\tau^{D}=\tau^{B}=\left[(a+t)\left(\mu_{1}^{h} \theta-\mu_{1}^{\gamma} \mu_{2}^{h}\right)\right] /\left[2\left(\mu_{2}^{\gamma} \mu_{2}^{h}-\theta^{2}\right)\right]$.
} 
provide better outcomes in terms of aggregate welfare.

The model can be extended in many directions. First, the emission rate at the sector level can be endogenous, by considering abatement technologies. Second, policymakers' environmental concerns can be also endogenous, by making political economy processes explicit, at the country or sector level. Third, one can consider sector differences in emission rates across countries. Last, additional features can be adopted, for example by following the various avenues of the GOLE literature (e.g., comparative advantage, multi-product firms, cross-border mergers, labor unions, wage inequality). The model presented here is just the tip of the iceberg of what one can do with the GOLE framework to analyze environmental issues. I hope to have stimulated this research avenue.

\section{References}

Baldwin, R.E., 1987. Politically Realistic Objective Functions and Trade Policy PROFs and Tariffs. Economics Letters 24, 287-290.

Baldwin, R.E., Evenett, S.J. (Eds.), 2009. The Collapse of Global Trade, Murky Protectionism, and the Crisis: Recommendations for the G-20. A Vox.EU.org Publication. Centre for Economic Policy Research (CEPR), London.

Barrett, S., 1994. Strategic Environmental Policy and International Trade. Journal of Public Economics 54, 325-338.

Bastos, P., Straume, O.R., 2012. Globalization, Product Differentiation and Wage Inequality. Canadian Journal of Economics 45, 857-878.

Burguet, R., Sempere, J., 2003. Trade Liberalization, Environmental Policy, and Welfare. Journal of Environmental Economics and Management 46, 25-37.

Colacicco, R., 2015. Ten Years of General Oligopolistic Equilibrium: A Survey. Journal of Economic Surveys 29, 965-992.

Conrad, K., 1993. Taxes and Subsidies for Pollution-Intensive Industries as Trade Policy. Journal of Environmental Economics and Management 25, 121-135.

Dixit, A.K., Grossman, G.M., 1986. Targeted Export Promotion with Several Oligopolistic Industries. Journal of International Economics 21, 233-249.

Egger, H., Etzel, D., 2012. The Impact of Trade on Employment, Welfare, and Income Distribution in Unionized General Oligopolistic Equilibrium. European Economic Review 56, 1119-1135.

Egger, H., Meland, F., Schmerer, H.J., 2015. Differences in the Degree of Unionization as a Source of Comparative Advantage in Open Economies. Canadian Journal of Economics 48, $245-272$. 
Elbers, C., Withagen, C., 2002. Environmental Stringency and Bertrand Competition: A General Equilibrium Approach, in: Hommes, C., Ramer, R., Withagen, C. (Eds.), Equilibrium, Markets and Dynamics. Springer, Berlin, pp. 183-195.

Elbers, C., Withagen, C., 2003. Environmental Policy and International Trade: Are Policy Differentials Optimal?, in: Marsiliani, L., Rauscher, M., Withagen, C. (Eds.), Environmental Policy in an International Perspective. Kluwer Academic Publishers, Dordrecht, Netherland, pp. 173-191.

Flam, H., Helpman, E., 1987. Industrial Policy under Monopolistic Competition. Journal of International Economics 22, 79-102.

Hummels, D., Skiba, A., 2004. Shipping the Good Apples Out? An Empirical Confirmation of the Alchian-Allen Conjecture. Journal of Political Economy 112, 1384-1402.

Irarrazabal, A., Moxnes, A., Opromolla, L.D., 2015. The Tip of the Iceberg: A Quantitative Framework for Estimating Trade Costs. Review of Economics and Statistics 97, 777-792.

Kee, H.L., Nicita, A., Olarreaga, M., 2009. Estimating Trade Restrictiveness Indices. Economic Journal 119, 172-199.

Kennedy, P.W., 1994. Equilibrium Pollution Taxes in Open Economies with Imperfect Competition. Journal of Environmental Economics and Management 27, 49-63.

Krugman, P., 1987. Is Free Trade Passé? Journal of Economic Perspectives 1, 131-144.

Leahy, D., Neary, J.P., 2011. Oligopoly and Trade, in: Bernhofen, D., Falvey, R., Greenaway, D., Kreickemeier, U. (Eds.), Palgrave Handbook of International Trade. Palgrave Macmillan, Basingstoke, UK, pp. 197-235.

Markusen, J., Morey, E., Olewiler, N.D., 1993. Environmental Policy when Market Structure and Plant Locations Are Endogenous. Journal of Environmental Economics and Management 24, 69-86.

Mayer, T., Ottaviano, G.I.P., 2008. The Happy Few: The Internationalisation of European Firms. Intereconomics: Review of European Economic Policy 43, 135-148.

Neary, J.P., 2003a. Globalisation and Market Structure. Journal of the European Economic Association 1, 245-271.

Neary, J.P., 2003b. The Road Less Travelled: Oligopoly and Competition Policy in General Equilibrium, in: Arnott, R., Greenwald, B., Kanbur, R., Nalebuff, B. (Eds.), Economics for an Imperfect World: Essays in Honor of Joseph E. Stiglitz. MIT Press, Cambridge, Massachusetts, pp. 485-500.

Neary, J.P., 2016. International Trade in General Oligopolistic Equilibrium. Review of International Economics (forthcoming), DOI: 10.1111/roie.12233.

Neary, J.P., Tharakan, J., 2012. International Trade with Endogenous Mode of Competition in General Equilibrium. Journal of International Economics 86, 118-132.

Palokangas, T., 2015. The Welfare Effects of Globalization with Labor Market Regulation. IZA Discussion Paper 9412. Institute for the Study of Labor (IZA). 
Rauscher, M., 1994. On Ecological Dumping. Oxford Economic Papers 46, 822-840.

Requate, T., 2005. Environmental Policy under Imperfect Competition: A Survey. Economics Working Papers 2005, 12. Christian-Albrechts-University of Kiel, Department of Economics.

Richter, Philipp, M., 2014. Strategic Environmental Policy in General Equilibrium. mimeo. DIW Berlin.

Sturm, D.M., 2003. Trade and the Environment: A Survey of the Literature, in: Marsiliani, L., Rauscher, M., Withagen, C. (Eds.), Environmental Policy in an International Perspective. Kluwer Academic Publishers, Dordrecht, Netherland, pp. 119-149.

Ulph, A., 1992. The Choice of Environmental Policy Instruments and Strategic International Trade, in: Pethig, R. (Ed.), Conflict and Cooperation in Managing Environmental Resources. Springer Verlag, Berlin, pp. 111-128.

Ulph, A., 1994. Environmental Policy and International Trade: A Survey of Recent Economic Analysis. Discussion Paper Series in Economics and Econometrics 9423. Economics Division, School of Social Sciences, University of Southampton.

WTO, 2012. Trade and Public Policies: A Closer Look at Non-Tariff Measures in the 21st Century. Technical Report. World Trade Report 2012. 